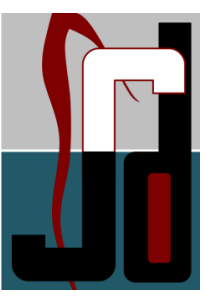

GASE REPORT

\title{
Surgical Orthodontic treatment of Skeletal Class II malocclusion
}

\author{
Hanumanth $\mathrm{S}^{1}$, U S Krishna Nayak ${ }^{2}$
}

\begin{abstract}
:
Traditional technique for correcting Class II in a growing patient is by growth modulation. In adults Class II discrepancy are treated either by orthodontic or comaflauge or by surgical correction. Class II discrepancies with mandibular deficiency are treated surgically by mandibular advancement surgery. Mandibular advancement by BSSO is found to be a stable procedure. An 18year old patient reported to the department with complains of forwardly placed upper front teeth. On examination patient had a retrognathic mandible with Class II relation. Intra orally patient had a Class II molar and incisor relation with increased overjet and overbite. The treatment plan of combination of orthodontics and surgery was employed to correct the discrepancy and obtain an aesthetic, harmonious facial profile. The mandibular advancement surgery was done which accomplished the objectives of the treatment.
\end{abstract}

Keywords: BSSO, Mandibular advancement surgery

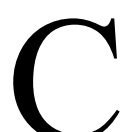

lass II malocclusion constitutes a significant percentage of cases to treat. Class II malocclusion usually can be treated by three methods 1) Growth modification to reduce the jaw discrepancy ${ }^{[1]}$ 2) Camouflage treatment by moving the tooth relative to the jaws to mask the underlying skeletal discrepancy ${ }^{[2]}$ 3) Surgical Orthodontic treatment whereby the repositioning of jaws are done to correct the skeletal discrepancy. ${ }^{[3]}$ In Children and adolescents growth modification with camouflage is employed for correction of the skeletal discrepancy. In adults where the growth potential is minimal skeletal discrepancies are treated by a combination of camouflage and surgery. ${ }^{[1,2,3]}$

This article describes a case treated by a combination of orthodontics and surgery.

\section{CASE REPORT}

An 18 year old patient reported to the Department of Orthodontics, A B Shetty Memorial Institute of Dental Sciences with complaint of forwardly placed upper front teeth. Clinical examination revealed a mesocephalic type with a convex facial 


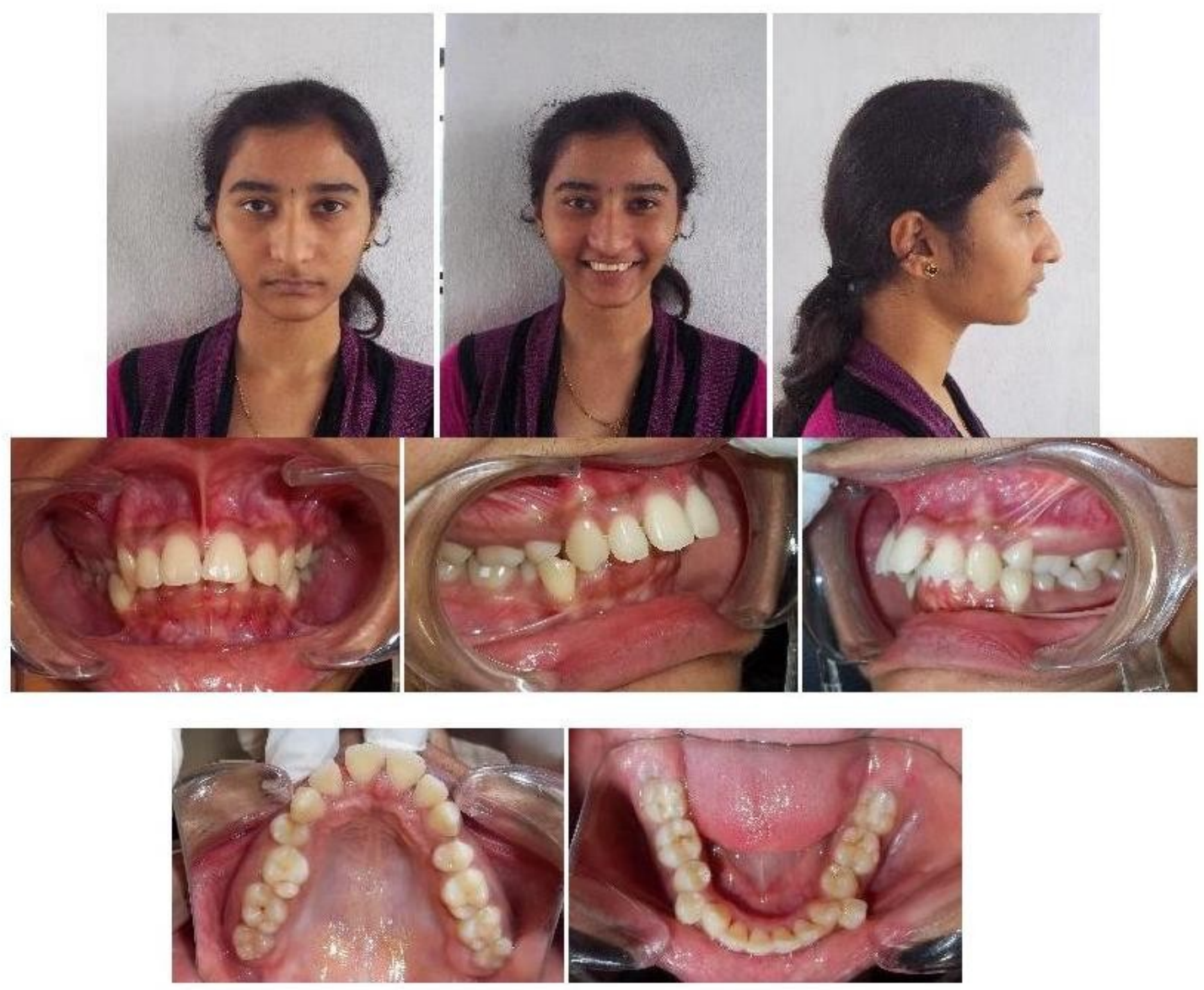

Fig-1: Pre Treatment photo
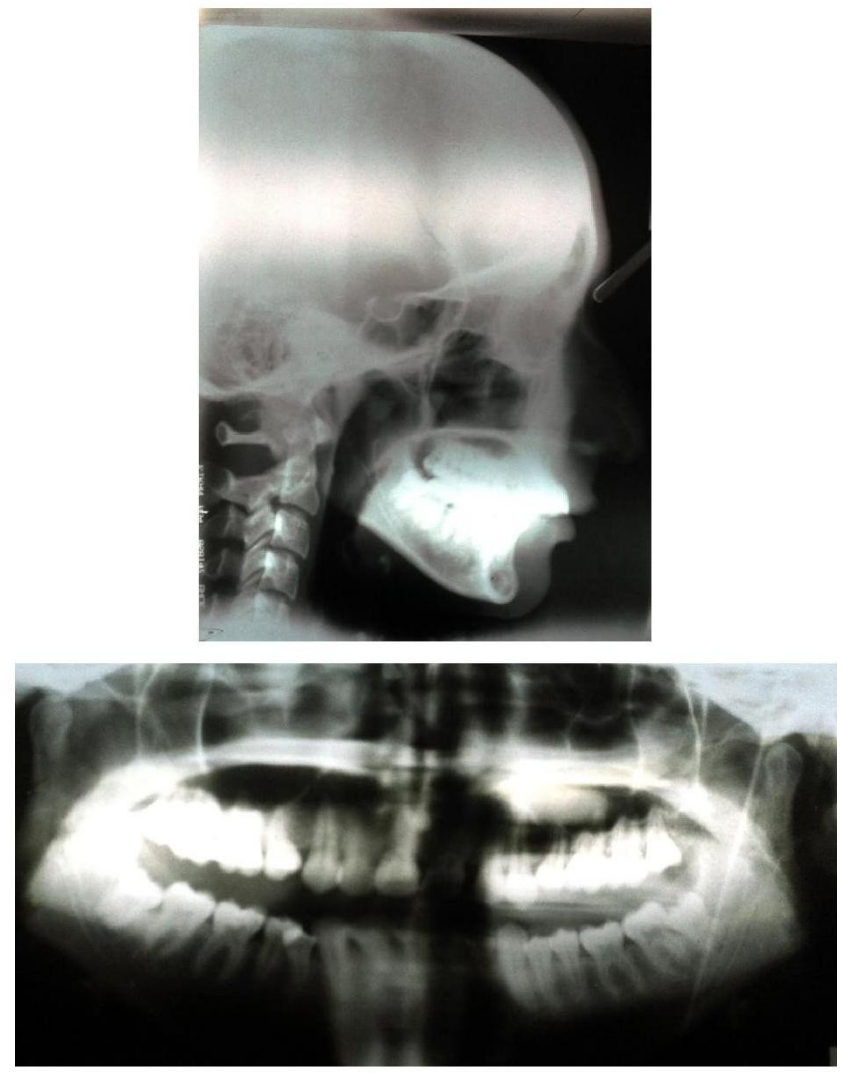

Fig- 1: Pre Treatment Radiographs - Lateral Cephalogram and OPG 

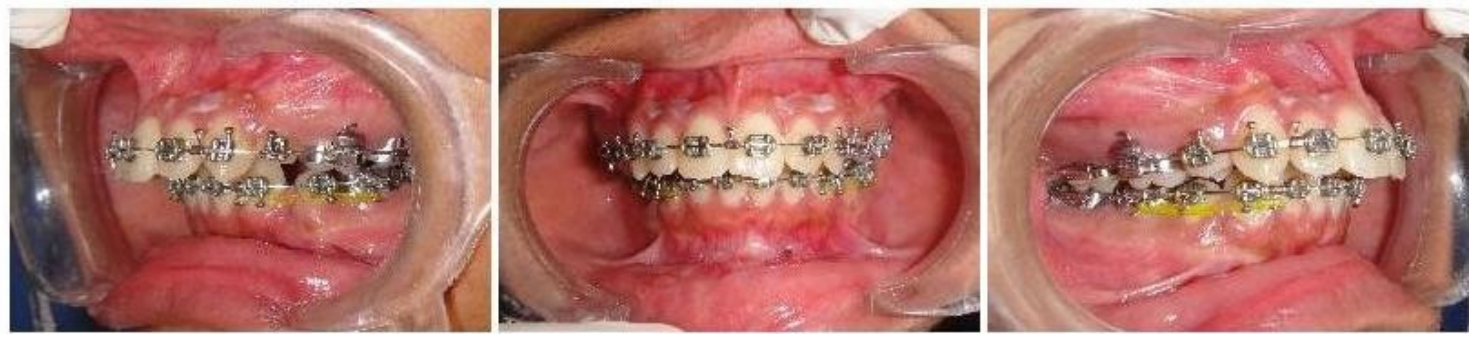

Fig- 3: Initial leveling and aligning, retraction
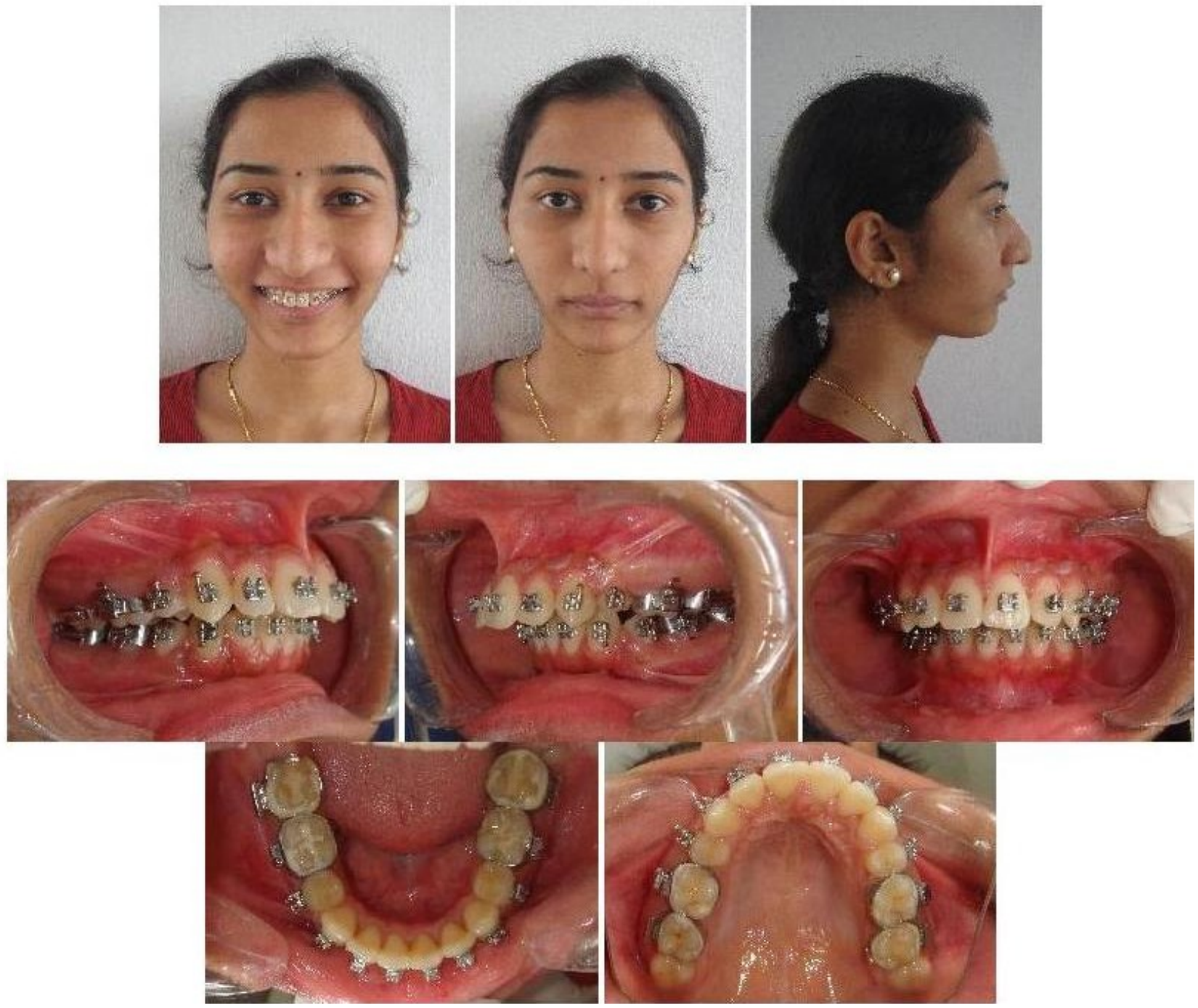

Fig- 3: Pre Surgical photo 

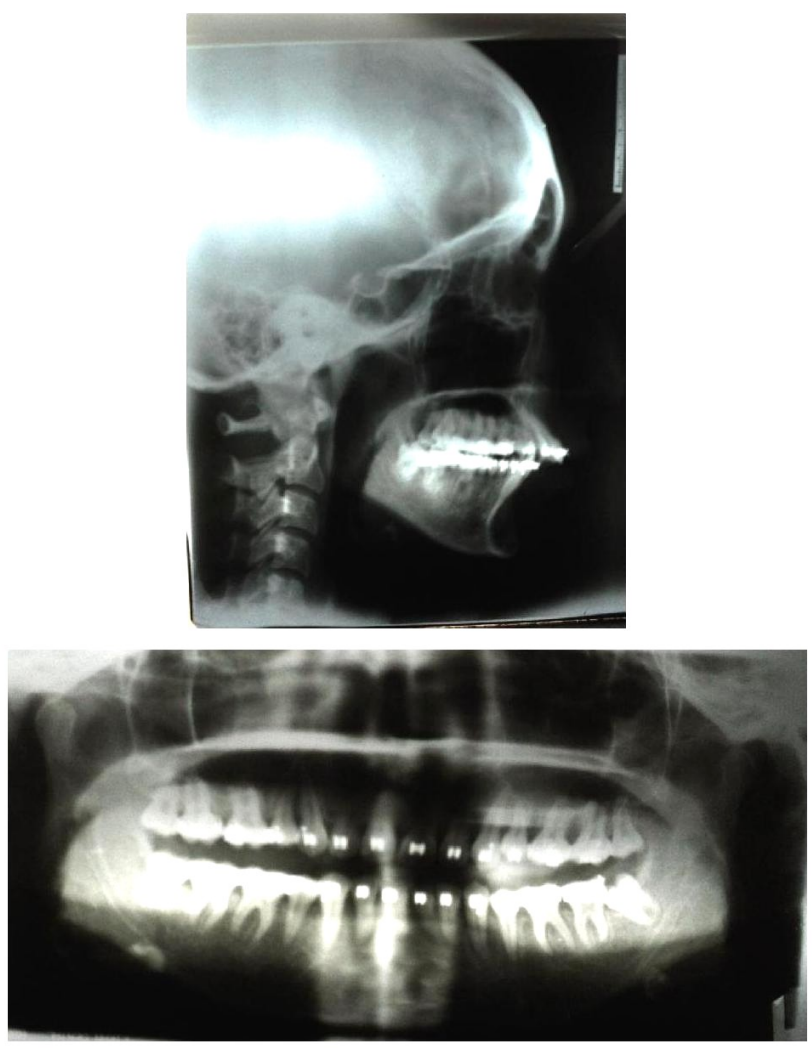

Fig- 4: Pre Surgical Radiographs - Lateral Cephalogram and OPG
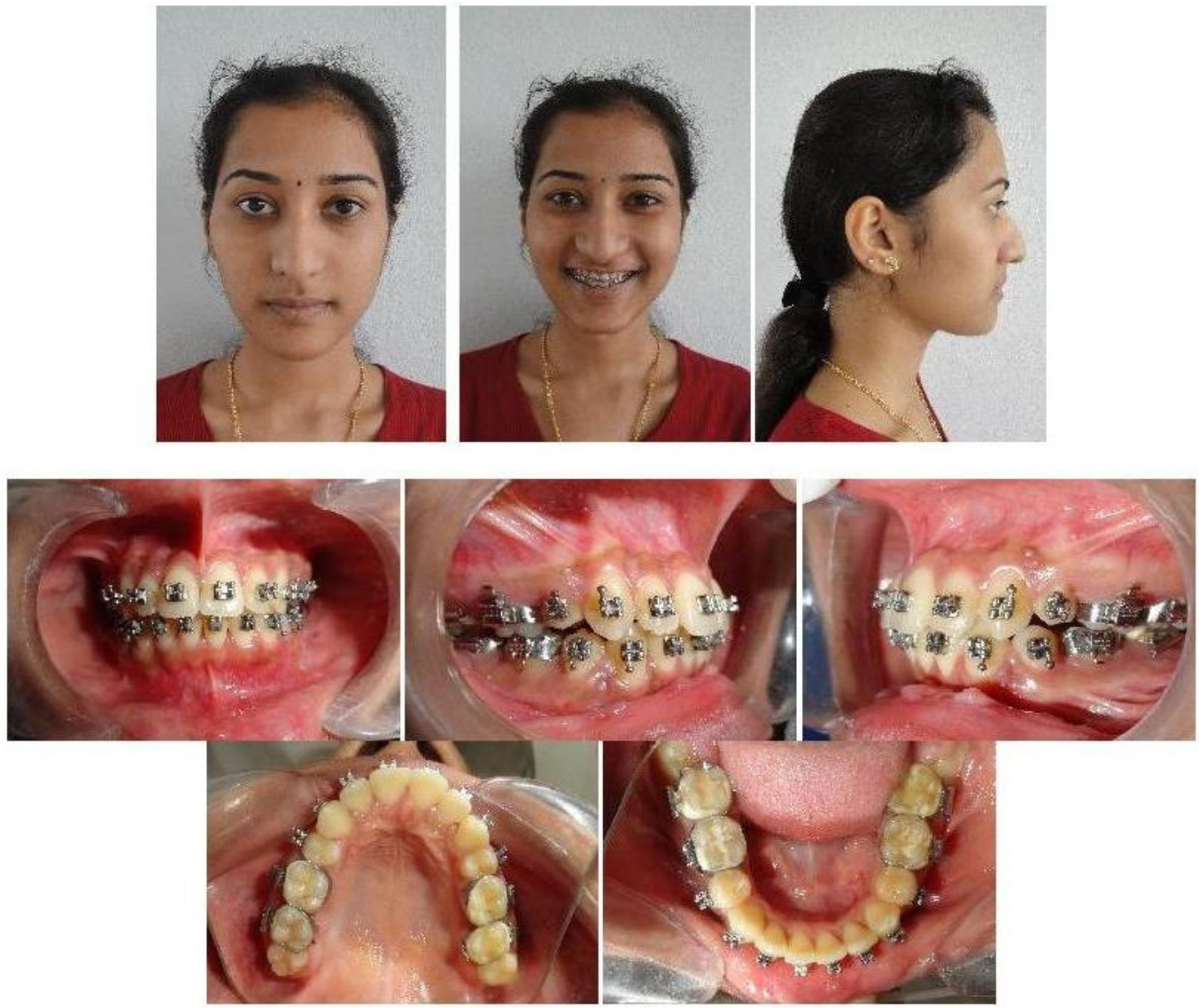

Fig- 5: Post Surgical photo 

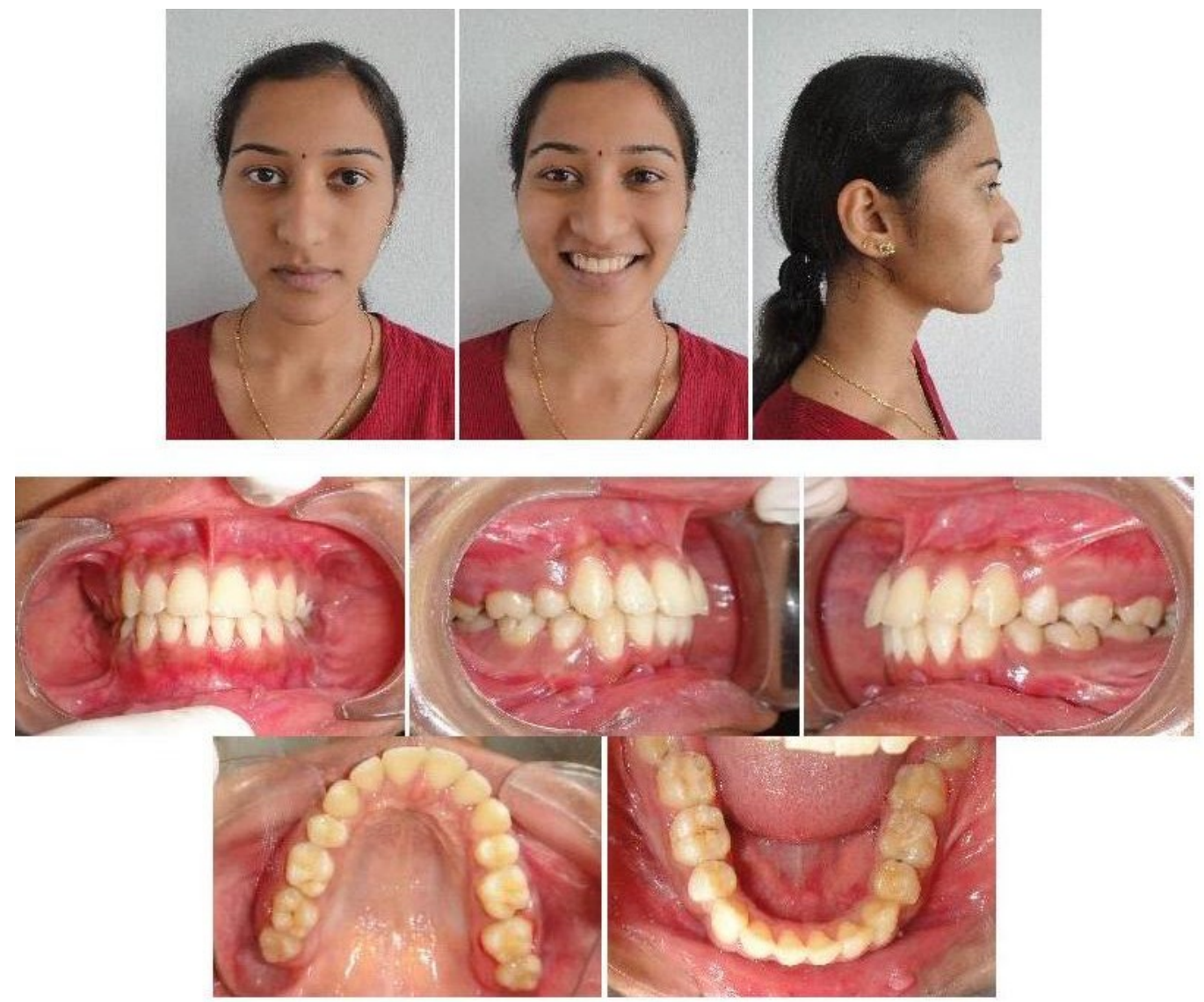

Fig-6: Post Treatment photo
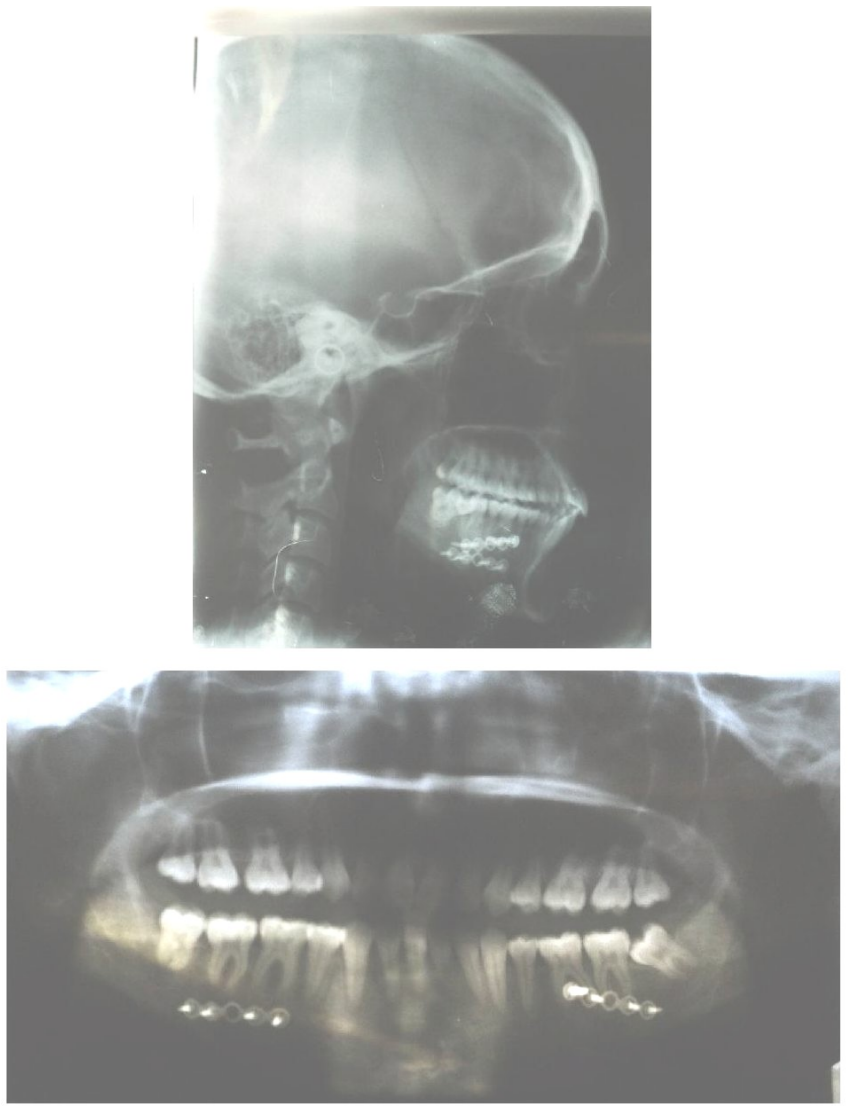

Fig- 7: Post Treatment Radiographs - Lateral Cephalogram and OPG 


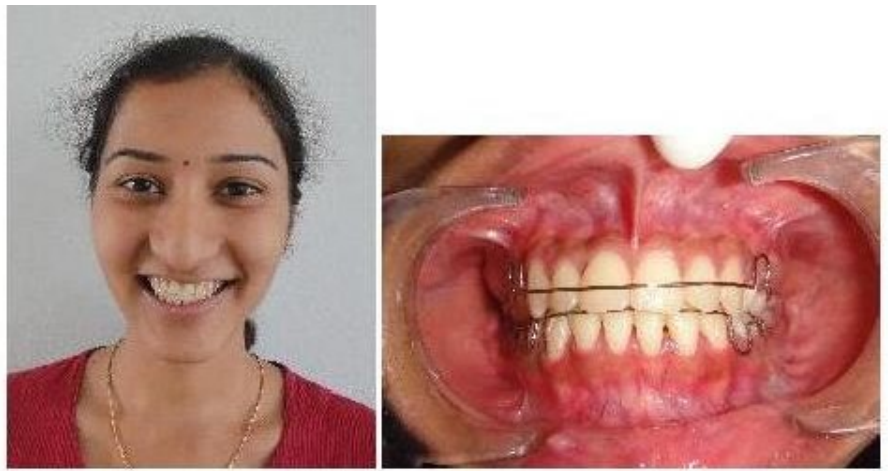

Fig- 8: Retainer Photograph

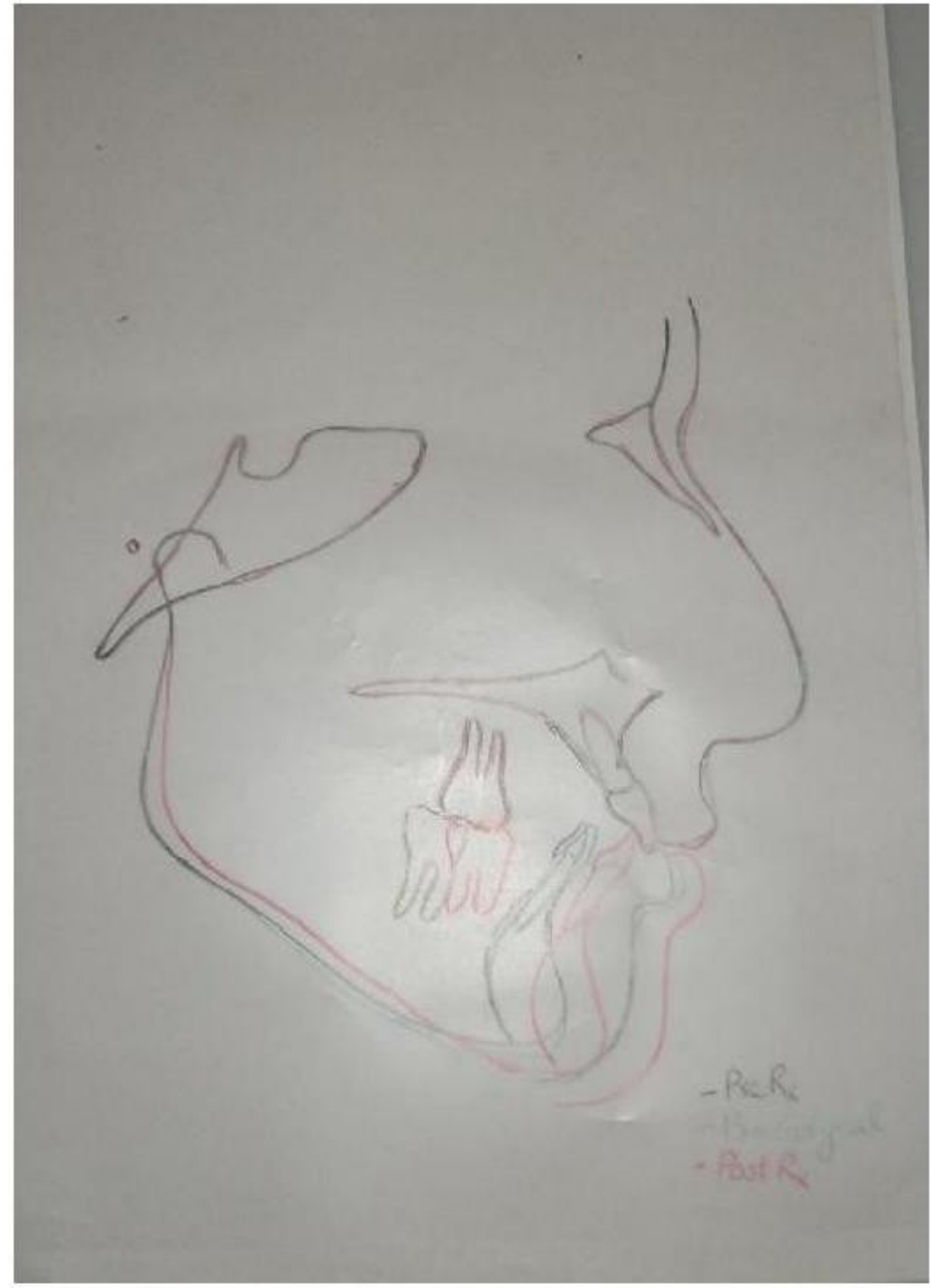

Fig- 9: Superimposition 


\begin{tabular}{|c|c|c|c|}
\hline Cephalometric Values & Pre treatment & Presurgical & Post Treatment \\
\hline SNA & 76 & 76 & 76 \\
\hline SNB & 71 & 70 & 75 \\
\hline WITS & 7 & 8 & 0 \\
\hline N-A-Pg & 6 & 5 & -2 \\
\hline Upper Incisor to NA & $40 / 7$ & $38 / 8$ & $38 / 9$ \\
\hline Lower Incisor to NB & $20 / 3$ & $29 / 5$ & $29 / 3$ \\
\hline Lower incisor to Mand. plane & 89 & 95 & 90 \\
\hline Inter-incisal Angle & 116 & 115 & 112 \\
\hline Nasolabial Angle & 90 & 92 & 110 \\
\hline Upper lip to E line & -4 & -4 & -6 \\
\hline Lower lip to E line & -6 & -6 & -3 \\
\hline Upper lip to S line & 1 & 1 & -1 \\
\hline Lower lip to Sline & -2 & -2 & 0 \\
\hline
\end{tabular}

\begin{tabular}{|l|l|l|l|}
\hline & PRETREATMENT & PRESURGICAL & POSTSURGICAL \\
\hline & & & \\
\hline CRANIAL BASE & & & \\
\hline Ar-Ptm & 33.5 & 33 & 33 \\
\hline Ptm-N & 60 & 61 & 61 \\
\hline HORIZONTAL & & & \\
\hline N-A-Pg & 6 & 5 & -2 \\
\hline N-A & -8 & -9 & -7 \\
\hline N-B & -23 & -25 & -14 \\
\hline N-Pg & -21 & -21 & -10 \\
\hline VERTICAL & & & \\
\hline N-ANS & 59 & 60 & 58 \\
\hline ANS-Gn & 66 & 68 & 71 \\
\hline PNS-N & 57 & 56 & 55 \\
\hline MP-HP(angle) & 28 & 30 & 32 \\
\hline 1-NF & 26 & 27 & 29 \\
\hline 1-MP & 46 & 45 & 45 \\
\hline 6-NF & 21 & 23 & 25 \\
\hline 6-MP & 33 & 34 & 33 \\
\hline
\end{tabular}

\begin{tabular}{|l|l|l|l|}
\hline $\begin{array}{l}\text { MAXILLA AND } \\
\text { MANDIBLE }\end{array}$ & & & \\
\hline PNS-ANS & 65 & 63 & 63 \\
\hline Ar-Go & 42 & 44 & 43 \\
\hline Go-Pg & 85 & 85 & 90 \\
\hline B-Pg & 9 & 10 & 11 \\
\hline Ar-Go-Gn(angle) & 115 & 114 & 130 \\
\hline DENTAL & & & 10 \\
\hline $\begin{array}{l}\text { OP-HP---U/L- occlusal } \\
\text { plane }\end{array}$ & 10 & 11 & \\
\hline A-B & 7 & 8 & 0 \\
\hline 1-NF & 125 & 125 & 120 \\
\hline 1-MP & 93 & 94 & 93 \\
\hline
\end{tabular}

Fig-10: Cephalometric values 
profile. The mandible was recessive with a flat mandibular plane angle. The patient had a deep mentolabial fold.

On Intra oral examination the patient had lower anterior crowding with bucally placed lower first premolars, class II molar relation and Class II division I incisor relation with an over jet of $12 \mathrm{~mm}$ and overbite of $8 \mathrm{~mm}$. [Fig 1]

The lateral cephalogram showed a skeletal Class II discrepancy with mandibular retrognathism, skeletal deep bite, reduced lower anterior facial height, proclined upper and lower incisors, an excessive lower curve of Spee. [Fig 2]

\section{Treatment Planning}

The treatment objective in this case was to achieve an aesthetically harmonious soft tissue profile by reducing the patient's facial convexity and increasing her lower facial height. The occlusal goals were to achieve a Class I molar relation, Class I incisor relation and obtain a normal over jet and overbite.

The patient was presented with option of mandibular surgical advancement with lower premolar extractions for which both the patient and the parent readily agreed.

The primary purpose of orthodontic treatment was to attain a Class I canine and molar relationship while maximizing the aesthetic impact of the surgical movements. The mandibular advancement surgery planned was a bilateral sagittal split osteotomy (BSSO), which is generally considered stable and predictable.

\section{Treatment progress}

The maxillary and mandibular arches were banded and bonded with 0.022 MBT [McLaughlin, Bennet and Trevisi] slot brackets. The initial levelling and aligning were done with 016 Niti, 018Niti, 16x22 Niti and 19x25 Niti.

After initial alignment, upper and lower 19x25 stainless steel wires were placed and lower anteriors were retracted using elastomeric chain . [Fig 3]

At the end of retraction the upper and lower arches were consolidated. Upper and lower 19x25 stainless steel wires were placed with crimpable hooks between the central incisors and between the canine and lateral incisors on each side. The brackets were ligated with stainless steel ligatures and were left in place for one month to express the bracket prescription.

The pre surgical records were taken at the end of pre surgical orthodontics. [Fig 4]

After the pre surgical orthodontic treatment was completed, mandibular advancement of $7 \mathrm{~mm}$ with bilateral saggital split osteotomy was performed under general anesthesia. The osteotomy cuts were place distal to the third molar on the lateral border of ramus. The osteotomy cuts were followed by 
repositioning the mandible to the desired position.

The separated bony segments was stabilised with titanium plates and screws. The patient was on post operative care for 4 days.

Post surgically the arch wires were removed and replaced with a new set of 19x25 stainless steel wires and were supplemented with box elastics bilaterally with Class II force vectors. [Fig 5]

After 5 months of finishing and detailing the appliance was debonded. Maxillary and mandibular wrap around retainers were given and final records were taken. [Fig 6, Fig 7, Fig 8]

\section{DISCUSSION:}

Treatment of Class II malocclusion in this case was by mandibular advancement surgery. The most common mandibular advancement surgery done is the bilateral saggital split osteotomy ${ }^{[3,4]}$. Class II malocclusion can be treated by a combination of maxillary and mandibular surgeries, maxillary surgery alone or by mandible surgery solely depending on the underlying skeletal discrepancy. $[5,6,7]$

Based on the clinical and cephalometric findings, the patient in this case report had a normal maxilla, retrognathic mandible with a class II relation. Dentally the upper anteriors were proclined whereas the lower anteriors were retroclined.

The overjet in this case was found to be $12 \mathrm{~mm}$. The mandibular surgery performed in this case showed an advancement of $7 \mathrm{~mm}$ as indicated by the change in Witts appraisal. The post treatment SNB and ANB value indicated a correction of Class II discrepancy in this case by mandibular advancement. [Fig 10]

The cephalometric superimposition showed Mandibular advancement of $7 \mathrm{~mm}$. There was significant improvement in the soft tissue profile indicated by the position of the upper lip, lower lip and the chin. Dentally Class I molar and Class I canine relation was seen. [Fig 9]

Mandibular advancement by BSSO is a stable procedure $^{[8,9,10]}$. However a long term observation is required in this case to ensure the stability of this procedure.

\section{CONCLUSION}

Class II malocclusions require careful diagnosis and treatment planning for a successful outcome. Here in this case report the Class II malocclusion was treated surgically by mandibular advancement. Significant improvement in the soft tissue profile was obtained in this case by mandibular advancement which added to the aesthetic value. Good occlusion at the end of treatment was achieved.

\section{REFERENCES}

1. Mc Namara, J.A. Components of Class II malocclusion in children 8-10 years of age. Angle Orthod 1981; 51: 177-202. 
2. Thomas P M. Orthodontic camouflage versus orthognathic surgery in the treatment of mandibular deficiency. J Oral Maxillofac Surg 1995 May; 53(5):57987.

3. Poulton DR, Ware HW. Surgical orthodontic treatment of severe mandibular retrusion. Part I. Am J Orthod 1971; 59:244-65.

4. Poulton DR, Ware HW. Surgical orthodontic treatment of severe mandibular retrusion. Part II. Am J Orthod 1973; 63:237-55.

5. Proffit WR, Phillips C, Dann C. Who seeks surgicalorthodontic treatment? Int J Adult Orthodon Orthognath Surg 1990; 5:153-60.

6. McNeill RW, West RA. Severe mandibular retrognathism: orthodontic versus surgical orthodontic treatment. Am J Orthod 1977; 72:176-82.

7. Proffit WR, White RP Jr. Mandibular deficiency in patients with normal or short face height. In: Proffit WR, White RP Jr, eds. Surgical-orthodontic treatment. St. Louis: CV Mosby, 1990:334- 77.

8. Mihalik CA, Proffit WR, Phillips C. Long term follow up of Class II adults treated with orthodontic camoflauge: A comparison with orthognathic surgery outcomes. Am J Orthod 2003; 123:266-78.

9. Bailey LJ, et al. Stability and predictability of orthognathic surgery. Am J Orthod 2004; 126:273.

10. Welch TB. Stability in the correction of dentofacial deformities: a comprehensive review. J Oral Maxillofac Surg 1989; 47:1142-49.
Address for correspondence:

Dr. Hanumanth S

Flat No 11, Second Floor,

Grace Apartments

177, Pappamal Koil Street, Vaithikuppam,

Pondicherry- 605012

E-mail - hanumanth001@gmail.com

\section{Authors:}

${ }^{1}$ Senior Lecturer,

Senior Lecturer, Department of Orthodontics, IGIDS

Pondicherry

${ }^{2}$ Professor and Head,

Professor,Dean Academics and Head

Department of Orthodontics

A B Shetty Memorial Institute of Dental Sciences, Mangalore

How to cite this article:

Hanumanth $\mathrm{S}^{1}$, U S Krishna Nayak ${ }^{2}$ Surgical Orthodontic treatment of Skeletal Class II malocclusion . Journal ofScien 1 tific Dentistry 2013;3(1):35-44

Source of Support: Nil, Conflict of Interest: None declared 